\title{
COMPREHENSIVE MEDICATION MANAGEMENT SERVICES IN A BRAZILIAN SPECIALTY PHARMACY: A QUALITATIVE ASSESSMENT
}

\author{
KIRLA BARBOSA DETONI' ${ }^{1}$ MARIANA MARTINS GONZAGA DO NASCIMENT0 ${ }^{1}$, ISABELA VIANA OLIVEIRA ${ }^{1}$, \\ MATEUS RODRIGUES ALVES ${ }^{1}$, MANUEL MACHUCA GONZÁLES ${ }^{2}$, DJENANE RAMALHO-DE-OLIVEIRA ${ }^{1}$
}

${ }^{1}$ Centro de Estudos em Atenção Farmacêutica (Center for Pharmaceutical Care Studies), Department of Social Pharmacy, College of Pharmacy, Universidade Federal de Minas Gerais, Belo Horizonte, Brazil, ${ }^{2}$ Universidad de Sevilla, Spain.

Email: kirladetoni@gmail.com

Received: 30 Nov 2016 Revised and Accepted: 30 Jan 2017

\section{ABSTRACT}

Objective: To understand and describe the implementation process of a comprehensive medication management (CMM) service in a public specialty pharmacy in Brazil.

Methods: Ethnographic study conducted over 17 mo (September 2014 to February 2016) in a public specialty pharmacy. Semi-structured interviews were conducted with twelve participants. Notes on field journals, resulting from participant observation conducted by the two pharmacists directly responsible for the service implementation, were also used as a source of data.

Results: Ten important conditions to improve the success of CMM service implementation were identified: manager support; evaluation of physical and material resources; evaluation of human resources practitioners' characteristics and knowledge about the theoretical framework of CMM services; time dedicated to CMM services; redefining the work process; defining patient eligibility criteria to CMM service; defining patient flow to CMM service; communication with healthcare team; integration with the staff; and marketing the service internally.

Conclusion: The results unveiled by this article can be used by pharmacists and managers as a tool to optimize the implementation of CMM services in different healthcare settings. These conditions do not consist the only aspects necessary to ensure the success of the service; however, they can contribute to optimize the implementation process of the practice.

Keywords: Pharmaceutical care, Medication therapy management, Comprehensive medication management services, Health services implementation, Qualitative research, Ethnography

(C) 2016 The Authors. Published by Innovare Academic Sciences Pvt Ltd. This is an open access article under the CC BY license (http://creativecommons.org/licenses/by/4.0/) DOI: http://dx.doi.org/10.22159/ijpps.2017v9i3.16398

\section{INTRODUCTION}

Comprehensive medication management (CMM) services [1-3] emerged in response to a social demand that traditional health services have demonstrated, which is the difficulty in resolving the marked increase in morbidity and mortality associated with the use of medications [4-9]. The World Health Organization estimates that, worldwide, over $50 \%$ of all medicines are inappropriately prescribed, dispensed or sold. Also, over $50 \%$ of all patients do not use them correctly [6].

CMM services have shown positive clinical, economic, and humanistic outcomes in many different settings around the world [10-16]. Given the need for this service driven by social demand, its implementation in different healthcare settings can be seen as imperative. Pharmacists in the public specialty pharmacy program in Brazil are in a strategic position to offer clinical services that can positively impact the outcomes of drug therapy. The program is part of the public health care system that represents a substantial proportion of health expenditure in Brazil [17]. Therefore, incorporation of CMM services can result in financial savings for the health care system $[10,12]$. In a 10 -year study conducted in a large integrated healthcare system in the United States, pharmacistestimated cost saving was US\$ 86 per encounter, and the total cost of CMM was US\$ 67 per encounter [10].

However, CMM services implementation in different practice settings remains a challenge. Implementation research in health represents a critical tool for providing scientific evidence to improve the expansion of healthcare services. This type of research aims to identify and refine strategies that can improve the implementation of health services in different settings [18-21]. In addition, it can expand the understanding on the operation of clinical services in the real world, helping to address a series of questions that arise in practice. Despite its evident importance, this research is overlooked worldwide [19]. This article sought to describe the implementation process of a CMM service within a specialty pharmacy unit in the state of Minas Gerais, Brazil. The study is discussed from the perspectives of the different actors involved in the process.

\section{MATERIALS AND METHODS}

\section{Setting description}

The specialty pharmacy program is a national program that is part of the public Brazilian healthcare system. Its goal is to guarantee access to free of cost quality medications in several dispensing units widespread over the country. High-cost medications for more than 80 specific medical conditions that are not covered by the primary care system are included in the scope of the program [22]. Following therapeutic guidelines, medications are periodically dispensed to patients after a specialist approval. This study was carried out in one dispensing unit, located in the state of Minas Gerais.

The specialty pharmacy staff is composed by pharmacy technicians (responsible for drug dispensing) and pharmacists (responsible for drug supply and logistics, drug dispensing and other administrative activities, including management of human resources). Two pharmacists with expertise in pharmaceutical care practice coordinated the implementation of the CMM service in the specialty pharmacy. They were appointed specifically to provide clinical services.

\section{Study design}

The ethnography methodology was adopted following the theory of Hammersley and Atkinson (1995) [23]. This approach entails an indepth holistic study that seeks to understand the culture of a specific group better. The ethnographer participates in the working lives of 
the individuals at the practice setting for a given period. During this time the investigator observes, listen and ask pertinent questions to elucidate the phenomenon under research, creating a rich understanding of social action and its subtleties in different contexts [23-25].

The fieldwork was undertaken for 17 mo (from September 2014 to February 2016). We employed multiple methods to collect data in this study: formal semi-structured interviews were combined with full participant observation and the whole process was permeated by reflective practice, thereby enriching the data. All of the events observed in the field were noted down in a field journal by both pharmacists responsible for the implementation of the service.

\section{Sampling}

To gain a broader overview of the process, narratives from a range of participants holding different positions within the pharmacy unit were included: two managers of the specialty pharmacy unit; four pharmacists from the staff team; two leaders of the pharmacy technicians' team; and four patients of the CMM service.

An intentional sampling was utilised in order to select the key informant interviewees based on their greater involvement in the implementation process. Intentional sampling is generally used in qualitative studies, by which the participants are chosen based on their ability to provide the richest information possible for investigating the phenomenon in depth [26]. Patient selection was carried out according to the following inclusion criteria: patients having participated in at least three CMM consultations and with the cognitive ability to understand questions to be asked during the interview.

The inclusion of the interviewees was made according to the criteria for data saturation, at which point further interviews no longer add new knowledge to the phenomenon under study [27]. A total of 12 participants were interviewed.

\section{Data collection}

All interviews were performed face-to-face by the first author and all of the participants invited agreed to participate in the study. The interviews were audio-recorded and transcribed verbatim. The average duration of each interview was 43 min, ranging from 14 to $75 \mathrm{~min}$. The questions of the topic guides for the semi-structured interviews were centred on two core topics: (1) understanding the facilitators and challenges during the CMM implementation process; (2) determining the viability and sustainability of the CMM at the specialty pharmacy unit. Data were also extracted from the field notes jotted down by the pharmacists responsible for the implementation of the service during the entire study period.

\section{Data analysis}

The data was analyzed and interpreted according to Hammersley and Atkinson (1995) [23]. The data analysis started at the moment the researcher has begun observing events and recording the field notes. All the interviews and the field notes were transcribed and analyzed several times, and meaningful extracted information was properly coded. The patterns identified in the coded data were then grouped into categories. Analysis and interpretation of the data were conducted primarily by the first author then validated in collaboration with the co-authors. To perform the data analysis, the software NVIVO®, version 10 , was used.

\section{Ethics considerations}

The present investigation was approved by the Ethics Committee of the Federal University of Minas Gerais, report $\mathrm{n}^{\circ} .25780314 .4 .0000 .0149 /$ 2014. The manager of the pharmacy unit also approved the study. Participation was voluntary, and all participants signed an informed consent form prior to participating in the study.

\section{RESULTS}

The extended fieldwork and the interviews revealed ten categories. They were grouped under a central category entitled "Optimising the implementation of CMM services: conditions to improve the success of the process". One of the categories contains two subcategories, totalizing eleven topics. These categories represent important conditions for a successful implementation of the CMM service. The formal definitions of each condition are summarized in table 1 and presented in details in the following sections according to the facilitators and challenges that emerged throughout the process.

\section{Management support}

Prior to commencing the provision of CMM services in the specialty pharmacy, the management support was essential, facilitating entry into the field and integration with the staff. During the interviews, the manager expressed her support and interest as a facilitator for CMM implementation in the specialty pharmacy:

I think that the major difficulty is to get the manager to accept. So as now I was the manager of the pharmacy, I said: "great, so now it can be done!"

However, the manager support should imply the active involvement of the managers as partners throughout the process, which should include CMM as an essential service in the pharmacy agenda. In other words, CMM should be recognized as vital to the mission of the business or pharmacy unit. In the studied specialty pharmacy, the lack of more active participation of the manager and the management team posed a challenge to the implementation of the service and this fact emerged in numerous reflections described in the field journals of the pharmacists in charge of implementation:

This fact makes me reflect that no matter how much we strive for the service to go well if the management is not fully committed, CMM runs the risk of not working out. This is out of our control. Even though the manager supports the service and we have the approval to do what we need to do, the management team is not fully involved.

Thus, the management team should participate in the process of setting up the goals, identifying the challenges, implementing the necessary fixes to the system and following up the outcomes of the service. These will make sure the entire team is engaged with the implementation process as it becomes a team effort.

\section{Evaluation of physical and material resources}

Each practice setting has unique characteristics, and the professional responsible for implementing the service must be aware of them. Taking this into consideration, the resources available and the viability of incorporating the service into the unit were assessed before the CMM service provision started. Initially, the pharmacists in charge took part in meetings with the manager and visited the setting several times. It was identified that the specialty pharmacy had adequate physical and material infrastructure to provide the service. This factor was mentioned by interviewees as a facilitator for CMM implementation. Participants highlighted the following as facilitators for CMM implementation: rooms for private patient consultations, availability of electronic documentation, and access to scientific information, including access to high-speed internet.

\section{Evaluation of human resources}

The rate limiting step for the success of CMM services is a wellprepared pharmacist practitioner. The evaluation of human resources should comprise the following factors: practitioners' characteristics and knowledge about the theoretical framework of CMM services.

\section{Practitioners' characteristics}

The interviewees underscored the need to identify, in the practice setting in which the CMM is to be implemented, practitioners that possess certain characteristics considered essential for clinical practice. This aspect is illustrated by the following sentence:

But you have to like it [the clinical practice]. Because there are those who (...) weren't cut out to work directly with patients, but are more suited to the logistic and administrative activities. (.) But first and foremost I think you have to find people with the right profile to be there.

The clinical pharmacists responsible for the implementation of the CMM showed real aspiration to deliver patient care. They were willing to take responsibility for the results of their decisions as well 
as to communicate with patients and other health care providers. Working directly with patients demanded the development of therapeutic relationships with patients, which was something considered very new for pharmacists. This fact may have positively influenced patients' perceptions of the consultations, increasing their satisfaction with the service. During the interviews, patients voiced their satisfaction with the CMM service, as shown in the excerpt below:

So, he [the patient] can talk about his doubts, right? Doubts that he normally wouldn't talk about with the physician (...) I feel like I'm inside an ideal clinic. I think that it should be like this in any kind of treatment, in any kind of contact with health professionals.

\section{Knowledge about the theoretical framework of CMM services}

With the exception of the pharmacists in charge of service implementation, the other pharmacists at the unit had no previous knowledge of CMM services. Considering this aspect, during the interviews, pharmacists recognized the need to train the future providers. Before providing a clinical service, the practitioner must have a well-structured knowledge about the philosophical, theoretical and methodological aspects of the professional practice that represents the foundation of the service, as well as knowledge of pharmacotherapy for a number of different health conditions. The pharmacists interviewed also pointed out that CMM providers must dedicate time to studying and acquiring this "new" type of knowledge:

If you are going to be the pharmacist running the CMM service, it's necessary to understand pharmaceutical care practice that is the foundation of everything we do... You also need to know how to access the clinical knowledge in order to perform CMM. (.) There's the issue of having time to study. You also have a group of diseases that are more common and you have to at least master these main diseases for you to know how you are going to conduct the practice.

\section{Time dedicated to CMM service}

The interviewees identified the fact that the pharmacist had to be in charge of managing both the CMM service and medication dispensing services as a major challenge:

There's no way of not ending up doing both jobs: the role of managing the dispensing unit and the role of attending the patient. It is a challenge.

Throughout the period of fieldwork, this challenge was evident. It reiterates the need for a pharmacist to be dedicated specifically to the provision of CMM services. One of the pharmacists, owing to the duality of functions, was not able to dedicate time for the clinical activities. The drug supply/logistic and administrative activities were her priority. Her duty was comprised almost entirely by filling in for other pharmacists whenever necessary. She reported that situation during the interview:

I had no chance to do it [CMM] because just when I got started, a pharmacist here would leave, then another one over there would too. I cannot let the service [management of drug dispensing] grind to a halt. I even said to the specialty pharmacy manager, "it's impossible".

\section{Redefining the work process}

The prolonged fieldwork demonstrated the need for the redesign of the work process within the place where CMM services are being implemented. The participants pointed out that it is necessary to develop the pharmacy technicians' autonomy in order to fully perform certain logistic functions that are still performed by pharmacists. As a consequence, pharmacists will have time available to dedicate to the clinical activities such as the provision of CMM services. Also important, as described by the interviewees, is the reorganization of the clinical and the administrative roles among the pharmacists. This becomes evident in settings where there is no pharmacist hired specifically for clinical practice. In this case, the work processes should be restructured in order to allow the professional to have allotted time to the provision of CMM services. The pharmacy manager illustrates this point:
Nowadays I have worked with the pharmacists here in terms of giving more autonomy to the pharmacy technicians, so they will be able to do the administrative job. This way, the pharmacists can invest their time in other activities, such as CMM.

However, according to the interviewees, this process was somewhat challenging, pointing to the resilience of the team as essential to move forward:

You have to change the whole structure of the unit. And then I see that people are really unwilling to make the slightest effort toward changing things for the better.

The above narrative stresses the fact that redefining pharmacists' work processes, which include adding new responsibilities towards patients, can often be seen as threatening. It is easier to keep doing what always have been done as compared to reinventing oneself and endeavoring towards uncharted waters.

\section{Defining patient eligibility criteria to CMM services}

Considering the high number of patients and medical conditions attended by the specialty pharmacy unit and the shortage of clinical pharmacists, it was impossible to make CMM services available to all patients. Thus, early in the implementation process, the following question arose: which group of patients should be eligible for the service? The clinical pharmacists noted the importance of prioritising more complex patients, who can benefit more from CMM:

Perhaps there are patients who need the CMM more than those we are seeing. Not that those we are seeing don't need it. They need it and we can see this from our results. But perhaps we could help even more.

Therefore, pharmacists decided to start their practice by offering the service to patients using multiple chronic medications and with several medical conditions.

\section{Defining patient flow to CMM services}

The results showed that reorganizing the flow of existing activities at the pharmacy was necessary for integrating CMM into the specialty pharmacy. As in many other healthcare settings, appointments with pharmacists are not generally part of the traditional roll of services, demanding the design of a patient flow consistent with the other existent activities:

That is something that we need to think about. Today we have a flow that is like this: patients come, and then they are attended by the pharmacy technician and then they leave. Right? If they want to talk to the pharmacist they can have access to the pharmacist; but there isn't a clinical service provided by the pharmacists in this flow, right? What could be done is to create this flow [to CMM service] (...). This way, when they come here, they [patients] can look for this service.

At the studied pharmacy, between different prospecting strategies, it was decided that the service would be offered to patients by telephone. Thus, patients that met the criteria for complexity would be a target to receive a phone call from technicians, pharmacy students or the clinical pharmacists themselves. The caller followed a scripted invitation. The CMM consultations were preferentially booked on the same day the patient went to the unit to get their medications. This was seen as a facilitator that encouraged initial adherence of the patient to the CMM service.

\section{Communication with health care team}

The peculiarities of each setting will call for different forms of communication with the healthcare team. In the specialty pharmacy, considering the absence of a multi-professional team, the contact with other health professionals were made through letters handed to the patients, who then delivered the note to the physician. The interviewees considered this alternative form of communication the most suitable for the service. For them, the operation of CMM requires the establishment of effective communication with the prescriber and other health professionals:

I can't see another way of communicating with the physicians, except through the letters. There are no other means right now. I say this 
because I have tried to make contact with clinics and hospitals. (.) We only get to speak to that professional who answered the phone. But is this person actually going to pass that information on? The information goes astray.

\section{Integration with the staff}

Efforts must be made with the objective to integrate the CMM service with the other activities developed in the practice setting and with the other members of the staff. The interviews and participant observation revealed the need felt by the pharmacy staff, including the pharmacists and the technicians, to be involved in the CMM service. They pointed out that the CCM service also relies on them:

You [clinical pharmacist] are the ones providing this service here, but we are also part of it because sometimes you depend on us to refer a patient to the service, right? Or gather data and so forth. So, we think that your interaction with the rest of the employees should be positive so that they can interact with the service.

Because they [pharmacy technicians] are part of the service, aren't they? They are not separate from the service [CMM].

\section{Marketing the service internally}

Throughout the process of participant observation, it was evident that, even after CMM was operating for some time, many staff members were still unaware of the service. One of the clinical pharmacists wrote in her field journal: "it's like I continue to be anonymous to most of the technicians". Indeed, the service was presented to the pharmacy staff after its implementation started, leading to breakdowns in internal communication:

The main thing I saw was the communication issue. (.) But I think that perhaps, improving this internal communication a bit, for everyone to be up to speed and know how it works, helps the patient.

One marketing strategy highlighted by the interviewees involved the reporting of the results of the service (clinical, economic and humanistic) to the pharmacy staff:

So, as soon as you start to show the results, you have concrete data, this builds credibility. This shows the importance of the service.

\section{Table 1: Description of the conditions to improve the success of comprehensive medication management (CMM) services implementation}

\begin{tabular}{|c|c|}
\hline $\begin{array}{l}\text { Conditions to improve CMM } \\
\text { implementation }\end{array}$ & Description \\
\hline Management support & Guaranteeing the support of the management team before starting the implementation process. \\
\hline $\begin{array}{l}\text { Evaluation of physical and material } \\
\text { resources }\end{array}$ & $\begin{array}{l}\text { Evaluation of the flow of activities in the setting, availability of physical infrastructure compatible } \\
\text { with a CMM service and accessibility to material resources. }\end{array}$ \\
\hline Evaluation of human resources & Identifying professionals that truly wish to be CMM providers. They will be more motivated, commit \\
\hline Practitioners' characteristics & more to the service and be more willing to deal with the challenges associated with providing the \\
\hline Knowledge about the theoretical & service. \\
\hline framework of CMM services & $\begin{array}{l}\text { Knowledge of the framework of pharmaceutical care practice, including the clinical method of } \\
\text { decision-making in pharmacotherapy. Knowledge of pharmacotherapy. }\end{array}$ \\
\hline Time dedicated to CMM services & $\begin{array}{l}\text { A quality CMM service is not achievable when the professional is concomitantly involved in technical- } \\
\text { administrative as well as clinical functions. }\end{array}$ \\
\hline Redefining the work process & $\begin{array}{l}\text { Redefining work processes among pharmacy technicians and pharmacists, allowing the introduction } \\
\text { of a clinical service in the setting. }\end{array}$ \\
\hline $\begin{array}{l}\text { Defining patient eligibility criteria for CMM } \\
\text { services }\end{array}$ & $\begin{array}{l}\text { Identifying patients that can benefit the most from the CMM service, taking into consideration local } \\
\text { needs. }\end{array}$ \\
\hline Defining patient flow to CMM services & $\begin{array}{l}\text { Analyzing patient flow and determining how they are going to reach the CMM service, be referred to } \\
\text { it and what changes in the traditional flow will be necessary. }\end{array}$ \\
\hline Communication with health care team & $\begin{array}{l}\text { Defining the best way of communicating with other health care professionals considering the } \\
\text { peculiarities of each setting. }\end{array}$ \\
\hline Integration with the staff & $\begin{array}{l}\text { Promoting the involvement and support of the local team, involving all staff. Identifying professionals } \\
\text { that can work as partners. }\end{array}$ \\
\hline Marketing the service internally & $\begin{array}{l}\text { Presenting the project of the service to the whole staff before commencing implementation. } \\
\text { Promoting constant marketing of the service to patients, local staff (internal public) and to other } \\
\text { health professionals (external public). }\end{array}$ \\
\hline
\end{tabular}

\section{DISCUSSION}

This qualitative study revealed conditions that could optimize the implementation of CMM services. This was identified through interviews along with participant observations as well as researcher reflexivity. The variety of participants allowed a broad view of the process from different perspectives. Also, it should be noted that these eleven conditions are interconnected, where shortcomings in one can affect the other.

The data highlighted the importance of having a plan prior the implementation of a clinical service, ensuring greater efficiency during this process. It is important to know the place, its people, their values and work processes, which will allow creating a plan that is harmonious with the culture of the place. Also, it is crucial to have allies that will make the process smoother.

Studies have shown that in successful CMM services the pharmacists have the support of the managers, confirming the importance of management support [28]. In this study, the support of the management team was considered pivotal to commencing the implementation process. A strategy is required when presenting the proposal of the service to the manager. The pharmacist must be aware of the current concerns of the manager so that the provision of the CMM is compatible with the local needs. Knowledge of the economic, clinical and humanistic benefits of the CMM service, extensively reported in the national and international literature, is essential [6-12]. Moreover, even after the initial approval of the project to implement the new service, the implementers should make sure that the management team is actively involved throughout the entire process and that CMM services become an important part of the mission of the business.

To achieve an effective implementation, previous understanding of the physical infrastructure and human resources, the flow of services and local activities including patient flow, of the existing site is required. It is vital to assess the viability of the service within the setting before starting the process, considering the requirements for building a clinical practice. In order to run a CMM service, adequate rooms for individual consultations, that were available in the study setting, are essential. The availability of private rooms allows patients to recognize the CMM as an organized, professionally run service that safeguards the privacy of the users [29].

Also, a documentation system and access to quality scientific information are prerequisites for a high-quality service. 
The current situation of the pharmacy profession in Brazil, and in most countries, presents some initial challenges to the implementation of pharmacist-based clinical services. The majority of the Brazilian pharmacists are not prepared for the provision of clinical services, and they are not fully integrated into the health care team. For the most part, they are not expected to work directly with patients. In a variety of settings, the pharmacist's role is focused strictly on drug dispensing. As described by Strand et al. (2004), it is "necessary to transform the pharmacist from a predominantly product-focused employee into a patient-centered care provider" [30].

The results of this ethnographic experience are in agreement with international recommendations stating that choosing practitioners who have specific qualities to provide direct patient care should be a priority action in the process of setting up a CMM service [29,31]. Preparing a new generation of clinical pharmacists involves a major transformation in the way the professional thinks and behaves. For this change to take place, it is crucial that the pharmacist truly embodies the philosophy of pharmaceutical care and assumes this as his or her professional mission [32]. The paradigm shift requires changing the focus from the product (medication) to the patient.

Studies conducted nationally and internationally highlight the lack of confidence of pharmacists in delivering services directly to patients and the need for them to develop specific skills for the clinical practice [33-36]. Besides understanding the theoretical and philosophical foundation of the professional practice, these skills include knowledge about the pharmacotherapy for a number of different medical conditions [30]. The participants of this study emphasized the need for training the pharmacist involved in the delivery of CMM services. In addition, the mastering of the components of pharmaceutical care practice allows the practitioner to employ well-founded arguments to present the service to managers, other members of the practice setting, other health professionals and patients. In addition, the use of a systematic clinical method ensures standardization of the work processes of practitioners, an increase in work efficiency, facilitates training and contributes for the social recognition of the practice [28].

Akin to the present study, there appears to be a consensus in the literature about the need to separate the management system of CMM services from that of dispensing [1,2]. It is well known that the goals and the measures of success for these activities are very different. According to Schommer et al. (2008), community pharmacists in the United States cited the burden of dispensing activities as one of the main factors preventing them from providing CMM services [37]. This same phenomenon was observed during the implementation of CMM at the specialty pharmacy.

Therefore, the results of this article reiterate the need to identify a pharmacist whose time is dedicated solely to clinical consultations. However, this is often not possible since the same practitioner is expected to perform administrative and clinical roles. In these cases, defining shifts with specific times for each activity is essential and has proved successful in some practices in the United States [28]. This reinforces the need to redefine work processes in the practice setting to allow time for the pharmacist to perform CMM, which was pointed out by the study participants.

Another important aspect when starting a CMM service is defining the eligible patients. The limited number of qualified practitioners for the delivery of CMM and the high demand of potential users of this service mean that specific groups of patients need to be prioritized. Many successful practice settings in the United States target patients that can benefit most from CMM services: individuals in use of several medications and who have multiple comorbidities [38]. The participants in this study also emphasized that prioritizing more complex patients for the service should be a strategy.

By concentrating on patients that most need the intervention of an CMM provider, the benefits of the services are reflected in positive clinical results more quickly [28]. However, the determining factors to successfully define the profile of patients to be attended can vary $[28,39,40]$. Patient selection criteria should be carried out in collaboration with team members, taking into consideration the peculiarities, needs and priorities of each setting.
During the process of implementing a totally new clinical service in the setting, the remodelling of the unit, both physically and in terms of the flow of activities, was necessary [29]. In the studied specialty pharmacy, the reorganization of patient flow in the unit was necessary and somewhat challenging. To facilitate this process, the flow of the CMM service must be fully compatible with the flow of the other activities in the practice setting. Thus, previous knowledge of the environment where the CMM practice is to be implemented is vital. Another aspect that emerged from this study regards the importance of the efforts of the practitioner to promote the integration of the CMM service with the other services and with the team.

The interviewees highlighted the desire to be involved in the implementation process where the openness of the team represents a facilitator. Costa and Pereira (2012) emphasized that the receptiveness and cooperation of the whole team is essential for implementing CMM services [41]. This reinforces the need to adopt adequate internal and external marketing strategies for the CMM services, which has the potential to integrate the internal team and involve the patient in the care process.

The operation of CMM services requires communication with physician and other members of the healthcare team [42]. In addition to the problems that can be solved directly with the patient (such as non-compliance to the regimen), the resolution of drug therapy problems often demands the introduction, suspension and/or changes in drug therapy. Therefore, the pharmacist should be able to build a relationship with other professionals using effective communication strategies [32].

The results of the study confirmed the viability of implementing CMM services in this specialty pharmacy unit in Brazil. To the best of the authors' knowledge, no other publications assessing the implementation of CMM services in the specialty pharmacy Program in Brazil exist in the literature. Given the wide array of different settings for implementing CMM services, each will have unique features that need to be recognised and individually assessed by the implementers. The methodology of the present study made possible to identify a vast range of criteria that were corroborated individually with other studies. Hence, we believe that the conditions outlined in this article should be considered by pharmacists during the implementation of CMM services in different practice settings.

Several strategies were adopted to minimise the inherent limitations of qualitative research: use of multiple methods of data collection (participant observation, field journals and interviews), prolonged immersion in the field, and selection of diverse participants for interviews, and collaborative data analysis and interpretation. However, it should be noted that this research was conducted in only one specialty pharmacy in one major city of Brazil, which can be seeing as a limitation of the study.

\section{CONCLUSION}

The conditions unveiled by this article can be used by pharmacists and managers as a tool to optimise the implementation of CMM services in different healthcare settings. Some of the key conditions that should be taken into consideration prior to CMM services implementation include guaranteeing manager support, ensuring time dedicated exclusively to the provision of CMM services and the importance of marketing the service internally and externally to the setting. These conditions do not represent all the necessary aspects to ensure the realisation of the service; however, they can contribute to the success of the implementation process of CMM services.

\section{CONFLICTS OF INTERESTS}

The authors have nothing to disclose.

\section{REFERENCES}

1. Ramalho-de-Oliveira D. Atenção farmacêutica: da filosofia ao gerenciamento da terapia medicaments a. 1st ed. São Paulo (SP): RCN; 2011.

2. Cipolle RJ, Strand L, Morley P. Pharmaceutical care practice: the patient-centered approach to medication management. $3 \mathrm{rd}$ ed. New York (NY): Mc Grand Hill; 2012. 
3. Patient-centered Primary Care Collaborative. Integrating comprehensive medication management to optimise patient outcomes; 2012.

4. Ernst FR, Grizzle J. Drug-related morbidity and mortality: updating the cost-of-illness model. J Am Pharm Assoc (Wash) 2001;41:192-9.

5. Who. Promoting the rational use of medicines: core components; 2002. Available from: http://apps.who.int/ medicine docs/ pdf/h3011e/h3011e.pdf. [Last accessed on 21 Mar 2016]

6. Stark RG, John J, Leidl R. Health care use and costs of adverse drug events emerging from outpatient treatment in Germany: a modelling approach. BMC Health Serv Res 2011;11:1-9.

7. Alhawassi TM, Krass I, Bajorek BV, Pont LG. A systematic review of the prevalence and risk factors for adverse drug reactions in the elderly in the acute care setting. Clin Interv Aging 2014;9:2079-86.

8. Johnson JA, Bootman JL. Drug-related morbidity and mortality: a cost-of-illness model. Arch Intern Med 1995;155:1949-56.

9. Nasution A, Khairunnisa, Tanjung HR. Drug therapy problems in the management of hypertensive outpatients admitted to four Indonesian primary health centres. Asian J Pharm Clin Res 2016;9:87-90.

10. Ramalho-de-Oliveira D, Brummel AR, Miller DB. Medication therapy management: $10 \mathrm{y}$ of experience in a large integrated health care system. J Manag Care Pharm 2010;16:185-95.

11. Obreli-neto PR, Marusic S, Guidoni CM, Baldoni AO, Renovato $\mathrm{RD}$, Pilger D, et al. Economic evaluation of a pharmaceutical care program for elderly diabetic and hypertensive patients in primary health care: a 36-month randomised controlled clinical trial. J Manag Care Pharm 2015;21:66-75.

12. Brummel A, Lustig A, Westrich K, Evans MA, Plank GS, Penso J, et al. Best practices: improving patient outcomes and costs in an aco through comprehensive medication therapy management. J Manag Care Spec Pharm 2014;20:1152-8.

13. Bunting $\mathrm{Ba}$, Smith $\mathrm{BH}$, Sutherland SE. The asheville project: clinical and economic outcomes of a community-based long-term medication therapy management program for hypertension and dyslipidemia. J Am Pharm Assoc 2014;48:23-31.

14. Schultz H, Westberg SM, Ramalho-de-Oliveira D, Brummel A. Patient-perceived value of medication therapy management (MTM) services: a series of focus groups. Inov Pharm 2012;3:1-8.

15. Mourão AOM, Ferreira WR, Martins MAP, Reis AM, Carrillo MR, Guimarães AG, et al. Pharmaceutical care program for type 2 diabetes patients in Brazil: a randomised controlled trial. Int J Clin Pharm 2013;35:79-86.

16. Ramalho-de-Oliveira D. Pharmaceutical care uncovered: An ethnographic study of pharmaceutical care practice; 2003.

17. Carias CM, Vieira FS, Giordano CV, Zucchi P. Medicamentos de dispensação excepcional: histórico e gastos do ministério da saúde do Brasil. Rev Saude Publica 2011;45:233-40.

18. Remme JHF, Adam T, Becerra-Posada F, D'Arcangues C, Devlin M, Gardner C, et al. Defining research to improve health systems. PLoS Med 2010;7:1-7.

19. Who. Implementation research for the control of infectious diseases of poverty; 2011. p. 1-147.

20. Peters DH, Adam T, Alonge O, Agyepong IA, Tran N. Republished research: Implementation research: what it is and how to do it. Br J Sports Med 2014;48:731-6.

21. Peters DH, Tran NT, Adam T. Implementation research in health: a practical guide. Alliance for Health Policy and Systems Research, World Health Organization; 2013.

22. Minstério da Saúde. Da exception alidade às linhas do cuidado; 2010. Available from: http://bvsms.saude.gov.br/bvs/ publicacoes/excepcionalidade_linhas_cuidado_ceaf.pdf. [Last accessed on 15 Mar 2016].

23. Hammersley, Martyn, Atkinson P. Ethnography. Principles in practice. 2nd ed. London and New York; 1995.

24. Prentice R. Ethnographic approaches to health and development research : the contributions of anthropology. In: Bourgeault I, Dingwall R, Vries R De. eds. The SAGE Handbook Qualitative Methods Health Research. London: SAGE Publications Ltd; 2014. p. 157-74.

25. Baumbusch JL. Conducting critical ethnography in long-term residential care: experiences of a novice researcher in the field. J Adv Nurs 2011;67:184-92.
26. Fontanella BJB, Luchesi BM, Saidel MGB, Ricas J, Turato ER, Melo DG. Sampling in qualitative research: a proposal for procedures to detect theoretical saturation. Cad Saude Publica 2011;27:389-94.

27. Martínez-Salgado C. El muestreo en investigación cualitativa: principios básicos y algunas controversias. Cien Saude Colet 2012;17:613-9.

28. McInnis T, Capps K. Get the medications right: a nationwide snapshot of expert practices. comprehensive medication management in ambulatory/community pharmacy. Vienna: Health2 Resources; 2016.

29. Willink DP, Isetts BJ. Becoming "indispensable": developing innovative community pharmacy practices. J Am Pharm Assoc 2005;45:376-89.

30. Strand L, Cipolle RJ, Morley PC, Frakes MJ. The impact of pharmaceutical care practice on the practitioner and the patient in the ambulatory practice setting: twenty-five years of experience. Curr Pharm Design 2004;10:39874001.

31. Silva DF. Universidade Federal De Minas Gerais Faculdade De Farmácia Programa De Pós-Graduação Em Ciências Farmacêuticas; 2015.

32. Martín-Calero MJ, Machuca M, Murillo MD, Cansino J, Gastelurrutia MA, Faus MJ. Structural process and implementation programs of pharmaceutical care in different countries. Curr Pharm Des 2004; 10:3969-85.

33. Dosea AS, Brito GC, Santos LMC, Marques TC, Balisa-Rocha $\mathrm{B}$, Pimentel D, et al. Establishment, implementation, and consolidation of clinical pharmacy services in community pharmacies: Perceptions of a Group of Pharmacists. Qual Health Res; 2015. p. 1-11.

34. Marquis J, Schneider MP, Spencer B, Bugnon O, Du Pasquier S. Exploring the implementation of a medication adherence programme by community pharmacists: a qualitative study. Int J Clin Pharm 2014;36:1014-22.

35. Pereira ML, Oliveira DR, Sebastião A, Coelho G, Cep C, Mg D. Da Teoria à prática: relatos da experiência de implantação da clínica de atenção farmacêutica em Minas Gerais, Brasil. Lat Am J Pharm 2009;28:869-75.

36. Brata C, Fisher C, Marjadi B, Schneider CR, Clifford RM. Factors influencing the current practice of self-medication consultations in Eastern Indonesian community pharmacies: a qualitative study. BMC Health Serv Res 2016;31:657-81.

37. Schommer JC, Planas LG, Johnson KA, Doucette WR. Pharmacist-provided medication therapy management (part 1): provider perspectives in 2007. J Am Pharm Assoc 2008;48:354-63.

38. Oladapo AO, Rascati KL. Review of survey articles regarding medication therapy management $(\mathrm{mtm})$ services/programs in the united states. J Pharm Pract 2012;25:457-70.

39. Lewin Group. Medication therapy management services: a critical review. J Am Pharm Assoc 2005;45:580-7.

40. Sushilkumar PL, Mahendrajumar BJ, Suman B, Chaitanya KT. Implementation and evaluation of health screening services to diabetic and hypertensive patients in a selected community pharmacy at Belgaum city. Asian J Pharm Clin Res 2016;8:305-15.

41. Costa JM, Pereira ML. Implementation of pharmaceutical care in a primary care unit of the unified health system in Brazil: Qualita 2012;15:287-93.

42. California Department of Public Health. Comprehensive medication management programs: description, impacts, and 2015 status in southern california; 2015.

\section{How to cite this article}

- Kirla Barbosa Detoni, Mariana Martins Gonzaga Do Nascimento, Isabela Viana Oliveira, Mateus Rodrigues Alves, Manoel Machuca Gonzáles, Djenane Ramalho-De-Oliveira. Comprehensive medication management services in a Brazilian specialty pharmacy: a qualitative assessment. Int J Pharm Pharm Sci 2017;9(3):227-232. 